\title{
STANDARDIZATION OF THE SUBSTRATE MATERIAL FOR LARGE SCALE PRODUCTION OF ARBUSCULAR MYCORRHIZAL INOCULUM
}

\section{SARANYA K* AND KUMUTHA K}

Department of Agricultural Microbiology, Directorate of Natural Resource Management, Tamil Nadu Agricultural University, Coimbatore, India, 641003, Ph: + 91 9791636870, + 91 9443817783, kkumuthatnau@yahoo.com

*Corresponding Author: Email - saran.miles2go@gmail.com

Received: May 16, 2011; Accepted: June 11, 2011

\begin{abstract}
Arbuscular Mycorrhizal (AM) fungi hold considerable potential for use as inoculant and nowadays much attention is focused on mass production of AM fungal inoculum, since this is of paramount importance in improving plant production in agriculture and horticulture. However, effectivity of these fungi on crop growth relies on their production practices, typically the substrate selected for its mass multiplication. Therefore, as an initial step, this experiment was carried out to select a suitable substrate for the AM (Glomus intraradices) inoculum production using maize (PEHM 5) as a host plant. Six different substrates namely biochar, biochar $+10 \%$ soil, vermiculite, vermiculite $+10 \%$ soil, vermicompost and vermicompost $+10 \%$ soil were tested with an uninoculated control in pot culture condition for the production of AM inoculum. Maize plants rose in vermicompost $+10 \%$ soil with the presence of AM fungi significantly showed an increase in the shoot length, root length, root biomass and nutritional status ( $\mathrm{N}$ and $\mathrm{P}$ ) over those grown in other substrates. The results also showed that vermiculite $+10 \%$ soil substrate produced the greatest colonization rate $(100 \%)$ and number of spores (726 / $50 \mathrm{~g}$ of substrate) compared to other substrates. Considering the results, it is suggested that vermicompost $+10 \%$ soil can be used as a substrate for large scale production of AM fungal inoculum.
\end{abstract}

Keywords: Arbuscular Mycorrhiza (AM), Glomus intraradices, inoculum, maize, substrate and production

\section{Introduction}

Arbuscular Mycorrhiza (AM) has been described as a "Universal Symbiosis" in plant kingdom. The beneficial effects of these intimate associations are many and are well documented. Arbuscular Mycorrhiza (AM) are symbiotic associations formed between Zygomycetes (Order- Glomales) and the roots of most terrestrial plants. These associations create an intimate link between plant roots and the soil in many types of natural ecosystems throughout the world. AM associations play an important role in the acquisition of mineral nutrients, specially the slowly mobile ions such as phosphorous (Abbott and Robson, 1984). In addition to growth promoting effects mainly due to efficient acquisition of mineral nutrients, it had been shown that AM plants are more resistant to biotic and abiotic stresses in nature (Sylvia et al., 1993; Al-Karaki and Al-Radded, 1997). Because of the added advantages, AM inoculum is widely used nowadays as bioinoculant in agricultural practices.

Artificial introduction of more efficient species of AM fungi into soils, where they are lacking or present in low numbers or inefficient species in the form of an inoculant, can improve the growth of many plants (Islam et al., 1980; Khan, 1972; Ibijbijen et al., 1996). However, since these fungi associated with Arbuscular Mycorrhizal cannot be grown on artificial synthetic media, the production of inoculum in large quantities has so far not been very successful. Therefore, AM fungal collections are maintained in living host plants under controlled conditions. Large scale multiplication of efficient fungi has been achieved by inoculating appropriate host plants such as clover, ray grass, sudan grass or maize that are grown in sterilized soil or any other rooting media such as clay, bark, pumice, peat mixtures and glass besds (Feldmann and Idezak, 1992; Vestberg and Uosukainen, 1992; Declerek et al., 1996). Spores, hyphae, infected root pieces and infested substate or rooting medium obtained from these cultures can be used either separately or in a mixture as a source of crude inoculum. One of the prime factors important for the effectivity of these fungi on crop is the substrate selected for its mass multiplication. For this reason, the majority of research groups try different substrates with nutrient solutions. But none has standardized a best substrate for AM inoculum production so that it can be adopted by companies. Therefore, we utilized maize as test plant in an experiment studying whether a) cheap sources of materials like inert material (vermiculite) or pyrolysis product from biomass (biochar) or enriched compost (vermicompost) could act as a best niche for the multiplication of AM fungi, b) amendment of $10 \%$ soil to the tested substrates supports AM fungal multiplication, as soil can act as a natural supplement of nutrients for both AM multiplication and host plant growth. The aim of the study was to standardize the substrate for AM inoculum production for commercial utility in large scales. 


\section{Materials and Methods Inoculum source}

The inoculum was a commercial product of Tamil Nadu Agricultural University, Coimbatore and contained a single species of AM fungus - Glomus intraradices (local - TNAU culture). The product consisted of fragments of colonized roots and spores of $\mathrm{AM}$ in vermiculite substrate material. This inoculum provided a uniform base for the substrate experiment, eliminating problems due to AMF batch variation.

\section{Substrate preparation}

The substrates used in this study were biochar, vermiculite and vermicompost with and without $10 \%$ amendment of field soil collected from field No 37 of the Eastern Block of Tamil Nadu Agricultural University located at Coimbatore, saline in $\mathrm{pH}$ (8.52), low in organic carbon (0.31\%), low in available $\mathrm{N}\left(191 \mathrm{~kg} \mathrm{ha}^{-1}\right)$, medium in available $\mathrm{P}\left(14 \mathrm{~kg} \mathrm{ha}^{-1}\right)$ and high in available K $(570 \mathrm{~kg}$ ha-1). Biochar prepared by the process of pyrolysis from acacia wood was obtained from Incrops Enterprise Hub, UEA, UK. The inert material vermiculite was supplied by Tamil Nadu Minerals, Chennai and the vermicompost was distributed by Department of Farm Machinery, TNAU, Coimbatore. The substrates were sterilized by autoclaving over $1 \mathrm{hr}$ using stepwise increase to ensure the centre reached $120^{\circ} \mathrm{C}$ for $30 \mathrm{~min}$ except vermicompost since it is expected to be rich in beneficial microbes which ensures increased plant growth.

The treatments were replicated five times in a new $1 \mathrm{~kg}$ plastic pot containing the respective substrate as per the treatments as follows: T1: Uninoculated control (Vermiculite alone), T2: Biochar + AM, T3: Biochar + $10 \%$ soil + AM, T4: Vermiculite + AM, T5: Vermiculite + $10 \%$ soil + AM, T6: Vermicompost $+\mathrm{AM}$ and $\mathrm{T} 7$ : Vermicompost $+10 \%$ soil $+\mathrm{AM}$.

\section{Inoculation with AM fungi}

About $5 \mathrm{~g}$ quantity of the AM inoculum source (containing an Inoculum Potential (IP) of 1500/g and 5-6 spores $/ \mathrm{g}$ ) was mixed into the top $4 \mathrm{~cm}$ of substrate in each pot. Each pot was planted with 3, sterile seeds of maize (PEHM 5). Once in 15 days each pot was treated with $20 \mathrm{ml}$ of $2 \mathrm{x}$ Hoagland solution minus phosphate (Hoagland and Arnon, 1938).

\section{Harvest and plant analysis}

After 60 days, the aerial part of the plants were removed and analyzed for its shoot length. The pots were dried for 2 weeks. Once the pots were dried, the roots were removed and the substrates were collected. The roots were measured for its length, weighed for its biomass and assessed for AM fungal colonization by the staining method described by Philips and Hayman (1980). Substrate samples $(50 \mathrm{~g})$ collected from each pot were subjected to wet sieving and decantation method of Gerdemann and Nicolson (1963) to estimate the population of AM spores. Also, shoot and root $\mathrm{P}$ and $\mathrm{N}$ concentrations were determined by employing the vanado molybdate phosphoric yellow colour and microkjeldahl methods respectively which modified from Jackson (1973).

\section{Statistics and experimental design}

Pots were arranged in a completely randomized block design in the green house. The data obtained were analyzed by a one factorial analysis of variance, with substrate as experimental factor using AGRES software as per described by by Panse and Sukhatme (1985). When the Fischer's values were significant, mean values were compared by Fisher's least square difference test $(P<0.05)$.

\section{Result \\ Effect of different substrates on the growth of host plant}

On perusal of the results, it was evident that although all pots inoculated with AM fungi produced spores, there were substantial differences in spore formation, AM infection and host plant growth between substrates. It was evident that amendment of $10 \%$ soil to the substrates significantly increased the growth of maize, AM root colonization, spore density and plant nutritional status. Among the treatments, vermicompost $+10 \%$ soil + AM combination was superior, which influenced the shoot length and root length of maize (Table 1). It recorded the maximum shoot length of $78.3 \mathrm{~cm}$ and root length of $31.1 \mathrm{~cm}$ with 45 and a $175 \%$ increase over control respectively at the time of harvest. In addition, the best root biomass was observed in vermicompost $+10 \%$ soil + AM followed by other treatment containing vermicompost $+\mathrm{AM}$. These two had significantly greater root biomass compared to the remaining five treatments, which were significantly different from each other (Table 2).

\section{AM root colonization and spore density in different substrate treatments}

Control plant in sterilized soil showed no AMF infections in roots and spore productions in the host plant. Typical Arbuscular Mycorrhizal structures such as vesicles, hyphae, arbuscules and coils were observed in all the substrates inoculated with AM fungi (Plate 1). These observations indicated that AMF were successfully infected in the roots of host plant employed in this work and all the substrates tested in this experiment can be utilized dependent upon their regional availability for AM mass multiplication. Mycorrhizal colonization of AM with biochar, vermiculite and vermicompost ranged at the level of $88-90 \%, 78-81 \%$ and $95-100 \%$ respectively. It showed significant difference among substrates used (Table2).

Mycorrhizal colonization was the highest in vermicompost amended with $10 \%$ soil. Similarly, a significantly higher spore load of 168 spores/ $50 \mathrm{~g}$ substrate was recorded in the treatment containing vermicompost $+10 \%+\mathrm{AM}$ compared to the other substrate materials. In $10 \%$ soil amended treatments, much increase in spore load numbers as well as root colonization was noticed than unamended substrates. 
However, when biochar was used as substrate such a difference was not noticed.

\section{Plant $\mathbf{N}$ and $\mathrm{P}$ concentrations}

With reference to shoot and root nutrient concentrations, use of different substrates had exhibited a significant influence on the plant $\mathrm{N}$ and $\mathrm{P}$ concentrations (Figure 1 ), and was further improved by the amendment of $10 \%$ soil to the substrate materials. Both $\mathrm{N}$ and $\mathrm{P}$ concentrations were significantly higher in plants grown in vermicompost and biochar compared to vermiculite. Both biochar + $10 \%$ soil $+\mathrm{AM}$ and Vermicompost $+10 \%$ soil $+\mathrm{AM}$ treatments registered 1-1.5 fold increase in root and shoot $\mathrm{N}$ concentrations and 1.5-2 fold increase in root and shoot $P$ concentrations of maize over a period of 60 days after planting.

\section{Discussion}

Substrate-based cultivation of AM fungi in pots, bags, or beds is the most widely adopted technique for AM fungal inoculum production because relatively low technical support is needed and consumables are cheap. Substrate based production systems are the least artificial and support the production of a large set of AM fungal species, either alone or in consortia of several species. In general, they are considered as a convenient system for large-scale production that is able to reach inoculum densities set for mass production of 80-100 propagules per cubic centimeter (Feldmann and Grotkass, 2002). When inert carrier media are used, the nutrient supplies to the AM fungus and plant can be monitored and regulated (Lee and George, 2005).

More controlled culture conditions are an advantage as this can lead to insights on factors to optimize propagule production. Various substrates either pure or mixed have been used to propagate and large-scale-produce AM fungi. Soil, often sandy, has been commonly reported (e.g., Douds and Schenck, 1990a, b; Sylvia and Schenck, 1983) as well as pure sand (e.g., Millner and Kitt, 1992) and to a lesser extent substitutes such as peat (e.g., Ma et al., 2007), glass beads (e.g., Lee and George, 2005; Neumann and George, 2005), vermiculite (e.g., Douds et al., 2006), perlite (e.g., Lee and George, 2005), compost (e.g., Douds et al., 2005, 2006), and calcinated clay (Plenchette et al., 1982). Substitutes for soil, sand, and substrate amendments have been considered for various purposes. For instance, relatively inert substrates (e.g., vermiculite and perlite) have been used to dilute nutrient-rich soil and compost (Douds et al., 2005, 2006). Conversely, compost or other organic substrates such as peat can be added to nutrientdeficient soils (Gaur and Adholeya, 2002; Ma et al., 2007). Many different organic amendments have been reported to influence AM fungal root colonization. Inert substrates have also been used as carrier medium to support roots and fungal growth under conditions where plant feeding was mainly provided by a nutrient solution (e.g., Lee and George, 2005).

\section{A. Growth response}

The study demonstrated that AM multiplication using maize as host plant varies significantly with the substrate used. The best results were obtained when vermicompost was used as substrate compared to biochar and vermiculite. The observations were proved to be maximum when the substrates were amended with $10 \%$ soil, especially in vermicompost. Vermicompost supporting effect on growth of maize compared to biochar and vermiculite may be due to its increased available nutrient content. Vermicast by itself is a natural nutrient rich organic supplement for crop growth. Another reason could have been the higher water holding capacity of vermicompost substrate with soil amendment (Perner et al., 2006). However, at least in the short term, the growth effect could also be partly attributed to microbial activities in the earthworm casts. Particularly, Tomati et al., (1988) demonstrated that earthworm casts have a hormone like effect, which can influence development of plants depending on amount and time of application and on plant species. Vermiculite showed reduced growth compared to vermicompost and biochar since it is an inert material without supporting any nutrients. Biochar too supported host plant growth since it is not only a nutrient rich substrate that act as a good microbial habitat and increase their survival, but it also add pointer to crop growth by enhancing the plant microbial interaction as reported by Warnock et al., 2007.

\section{B. Microbial response}

It is generally believed that vermicompost supports several beneficial microbes which can influence the growth of hyphae from germinating Arbuscular Mycorrhizal spores, colonization of plant roots and growth of external hyphae. It was also hypothesized that those microbes could soften the cell wall and the middle lamellae between the cells of the root cortex by producing enzymes and thus making fungal penetration easier. These results tend to indicate a sort of tropic stimulation of the fungal growth by the micro organisms present in vermicompost in the mechanism involved. Maximum spore count observed with the use of vermicompost as substrate with the amendment of $10 \%$ soil, highlighted the existence of synergistic interaction in the rhizosphere. It was explained that fungus could be suffering from auto inhibition by producing some fungistatic compounds, which could be metabolized by the accompanying microbes and this allows the growth of mycelium and spore production (Azcon-Anguilar and Bago, 1994). Additionally, it was recorded that, biochar also supported AM multiplication, the response of biochar on the native AM fungi is in conformation with the latest report of Harvey et al., 1976. It was found that AM fungi responded more positively to biochar additions than to additions of other types of organic material. Biochar has a high moisture holding capacity due to slow release of moisture from its sponge like matrix (Peitikeinen et al, 2000) which is the main fact that is instrumental for the higher survival rate of AM. Moreover, the reduced particle size and higher surface area of biochar especially produced from acacia wood 
dramatically act as a best nutrient rich substrate for AM multiplication (Lehmann et al., 2002).

\section{Nutrient factors}

Manipulation of nutrient regimes has been demonstrated to impact AM fungal propagule production (Douds et al., 2006; Douds and Schenck, 1990a, b). The nutrient content of the substrate as well as the addition of macronutrients and micronutrients may influence the AM fungi directly but also indirectly by the plant responses to nutrient availability, e.g., by altered root growth or photosynthesis. Although it remains largely unclear as to which extent the used plant/AM fungi associations differ in their nutrient requirements, optimal nutrient regimes support initial colonization, promote adequate plant (root) growth, and optimize the AM fungal propagule production. In this study, increased $\mathrm{N}$ and $\mathrm{P}$ supply as evidenced by the increased shoot and root nutrient concentrations of maize are the sole facts for its increased growth in terms of root biomass which act as a prime source for AM inoculum preparation. The available $P$ content of vermicompost would have been a reason to allow an AM dependent shoot enhancement effect. In case of $P$ concentrations of maize, a mycorrhizal effect is evident. This result corresponds with those of Nowak (2004) where mycorrhizal fungi increased the P uptake by plant and aided its growth as it supplies all the necessary nutrients. The results are also in conformity with the findings of Veeken et al., 2004 who found that compost is a best alternative to any substrates used for AM multiplication and it can act as a suitable niche for AM when amended with organic nutrient sources to meet the plant demand. Moreover, compost containing substrates is believed to be appropriate for mycorrhizal plants (Linderman and Davis, 2001) if the quality of the compost is adequate (Perner et al., 2006) in the form of vermicompost. Biochar too recorded higher $\mathrm{N}$ and $\mathrm{P}$ concentrations of maize. The results are in line with the findings of Lehmann et al., 2002 who reported that biochar additions resulted in higher $\mathrm{C}, \mathrm{P}, \mathrm{K}$ and $\mathrm{Zn}$ availability, and to a lesser extent $\mathrm{Ca}$ and $\mathrm{Cu}$ along with greater stabilization of organic matter, concurrent slower nutrient release from added organic matter and better retention of cations due to greater cation exchange capacity which results in immediate beneficial effects of biochar additions for nutrient availability resulting in AM multiplication, plant nutrient uptake, increased and host plant growth.

\section{Conclusion}

In a nutshell, the results of the study indicate that vermicompost is a suitable substrate for AM inoculant production commercially in large scale especially Glomus intraradices. This substrate may be useful in inoculum production of other species of AM as well. The effectivity of vermicompost on AM fungal multiplication can further be enhanced by the amendment of the substrate with $10 \%$ soil. Thus, vermicompost $+10 \%$ is suggested as the best substrate material for the mass production of AM inoculum as it is a nutrient rich material comprising of beneficial microbes that favor both mycorrhizal multiplication and host plant growth.

\section{References}

[1] Abbott L.K. and Robson A.D. (1984) The effect of VA mycorrhizal on plant growth. CRC Press, Baco Raton, Florida.

[2] Al-Karaki G.N. and Al-Raddad A. (1997) Mycorrhiza 7: 83-88.

[3] Azcon-Aguilar C. and Bago B. (1994) Physiological characteristics of the host plant promoting an undisturbed functioning of the mycorrhizal symbiosis. In: Impact of Arbuscular mycorrhizas on Sustainable Agriculture and Natural Ecosystems, pp. 47-60, edited by S Gianinazzi and H Schhepp BirkhäuserVerlag, Basel, pp-13.

[4] Declerek S., Strulla D.G. and Plenchette C. (1996) Mycological Research 10: 1237-1242.

[5] Douds D.D. and Schenck N.C. (1990a) Appl. Environ. Microbiol. 56:413-418.

[6] Douds D.D. and Schenck N.C. (1990b) New Phytol. 116:621-627.

[7] Douds D.D., Nagahashi G., Pfeffer P.E., Kayser W.M. and Reider C. (2005) Can. J. Plant. Sci. 85:15-21.

[8] Douds D.D., Nagahashi G., Pfeffer P.E., Reider C. and Kayser W.M. (2006) Biores. Tech. 97:809-818.

[9] Feldmann F. and Grotkass C. (2002) Directed inoculum production - shall we be able to design AMF populations to achieve predictable symbiotic effectiveness? In: Gianinazzi S, Schüepp H, Barea JM, Haselwandter K (eds) Mycorrhizal technology in agriculture: from genes to bioproducts. Birkhauser, Basel, pp 261-279.

[10] Feldmann and Idezak (1992) Inoculum production of vesicular - Arbuscular Mycorrhizal fungi for use in tropical nurseries. In: Methods in microbiology. Eds. Norris JR, Read DJ and Varma AK, Academic Press, London, pp 339-357.

[11] Gaur A. and Adholeya A. (2002) Biol. Fertil. Soils 35:214-218.

[12] Gerdemann J.W. and Nicolson P.H. (1963) Trans. Brit. Mycol. Soc. 46: 235 - 244.

[13] Harvey A.E., Jurgensen M.F. and Larsen M.J. (1976) Forest Sci. 22:350-358.

[14] Hoagland D.R. and Arnon D.I. (1938) The water culture method of growing plants without soil. California Agricultural Experiment Station, Circular 347, Berkeley, Calif.

[15] Islam R., Ayanaba A. and Sanders F.E. (1980) Plant and Soil 54: 107-117.

[16] Jackson M.L. (1973) Soil chemical analysis, Prince Hall of India (P) Limited, New Delhi. pp.103.

[17] Khan A.G. (1972) New Phytol. 71: 613-619.

[18] Lee Y.J. and George E. (2005) Hort.Science. 40:378-380.

[19] Lehmann J et al., (2002) Slash-and-char: A feasible alternative for soil fertility management in the central Amazon. In 17th World Cong. S. Sci. Bangkok. pp. 449. 
[20] Linderman R.G. and Davis E.A. (2001) Hort. Technology 11:446-450.

[21] Ma N., Yokoyama K. and Marumoto T. (2007) Soil Sci. Plant Nutr. 53:744-752.

[22] Millner P.D. and Kitt D.G. (1992) Mycorrhiza 2:9-15.

[23] Nowak J. (2004) Symbiosis 37:259-266.

[24] Panse V.G. and Shukatme P.V. (1978) Indian council of Agricultural Research, New Delhi,327.

[25] Perner H., Schwarz D. and George E. (2006) Hort. Science 41:628-632.

[26] Philips J.M. and Hayman D.S. (1970) Trans. Brit. Mycol. Soc. 55: 158-166.

[27] Pietikainen J., Kiikkila O. and Fritze H. (2000) Oikos 89: 231-242.
[28] Plenchette C., Furlan V. and Fortin J.A. (1982) J. Am. Soc. Hortic. Sci. 107:535-538.

[29] Sylvia D.M. and Schenck N.C. (1983) New Phytol. 95:655-661.

[30] Sylvia D.M., Hannond I.C. Bennett J.M. Hass J.H. and Linda S.B. (1993) Agron. J. 85: 193-198.

[31] Tomati U., Grapelli A. and Galli E. (1988) Biol. Fertil. Soils 5: 288-294.

[32] Veeken A., de Wilde V., Woelders H. and Hamelers B. (2004) Bioresour. Technol. 92:121-131.

[33] Vestberg M. and Uosukainen M. (1992) Mycologist 6: 138.

Table 1- Shoot length $(\mathrm{cm})$ and root length $(\mathrm{cm})$ of maize grown in different substrates inoculated with AM (Glomus intraradices) fungi at 2 months after inoculation

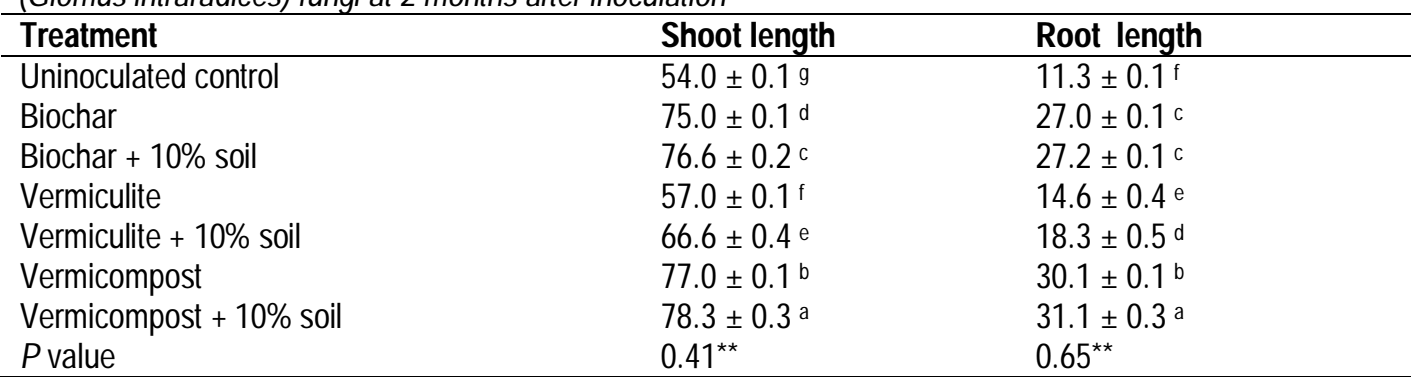

Values are means of five observations \pm standard error of the mean (SE); Means in the same column followed by different letters are significantly different; ** = highly significant.

Table 2- Root colonization (\%), Spore density (mean no. spores / $50 \mathrm{~g}$ of substrate) and root biomass ( $\mathrm{g}$ ) of maize grown in different substrates

\begin{tabular}{llll}
\hline Treatment & Root colonization & Spore density & Root biomass \\
\hline Uninoculated control & - & - & $0.41 \pm 0.005^{\mathrm{f}}$ \\
Biochar & $89 \pm 1^{\mathrm{c}}$ & $85 \pm 1^{\mathrm{c}}$ & $2.63 \pm 0.01^{\mathrm{c}}$ \\
Biochar + 10\% soil & $90 \pm 1.5^{\mathrm{c}}$ & $88 \pm 0.5^{\mathrm{c}}$ & $2.74 \pm 0.002^{\mathrm{b}}$ \\
Vermiculite & $78 \pm 1^{\mathrm{e}}$ & $54 \pm 0.5^{\mathrm{e}}$ & $0.98 \pm 0.03^{\mathrm{e}}$ \\
Vermiculite + 10\% soil & $81 \pm 0.5^{\mathrm{d}}$ & $72 \pm 2^{\mathrm{d}}$ & $2.24 \pm 0.01^{\mathrm{d}}$ \\
Vermicompost & $95 \pm 1^{\mathrm{b}}$ & $142 \pm 5^{\mathrm{b}}$ & $3.44 \pm 0.01^{\mathrm{a}}$ \\
Vermicompost + 10\% soil & & $168 \pm 3^{\mathrm{a}}$ & $3.47 \pm 0.01^{\mathrm{a}}$ \\
$P$ value & $100 \pm 1^{\mathrm{a}}$ & $4.81^{\star *}$ & $0.05^{\star \star}$ \\
& & & \\
& $2.09^{\star \star}$ & & \\
\hline
\end{tabular}

Values are means of five observations \pm standard error of the mean (SE); Means in the same column followed by different letters are significantly different; ** = highly significant. 
a) $\mathrm{N}$ content

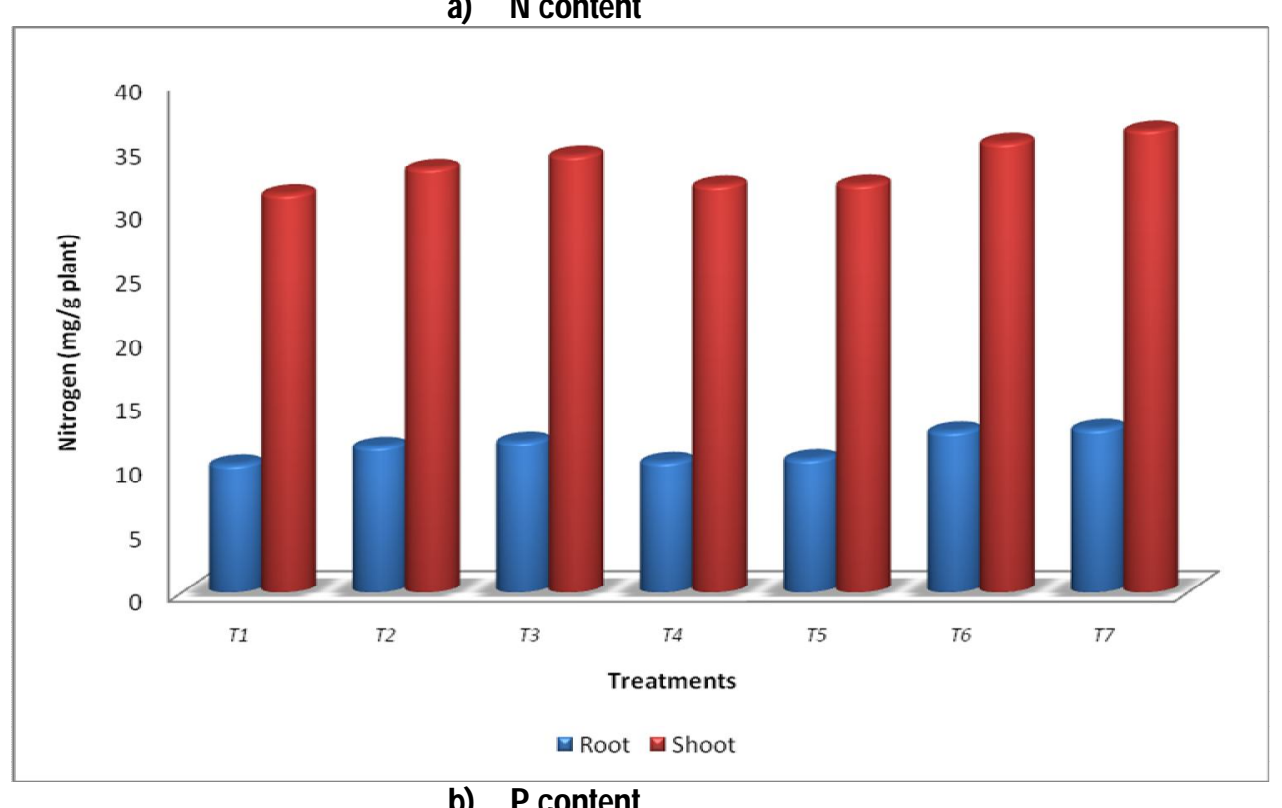

b) P content

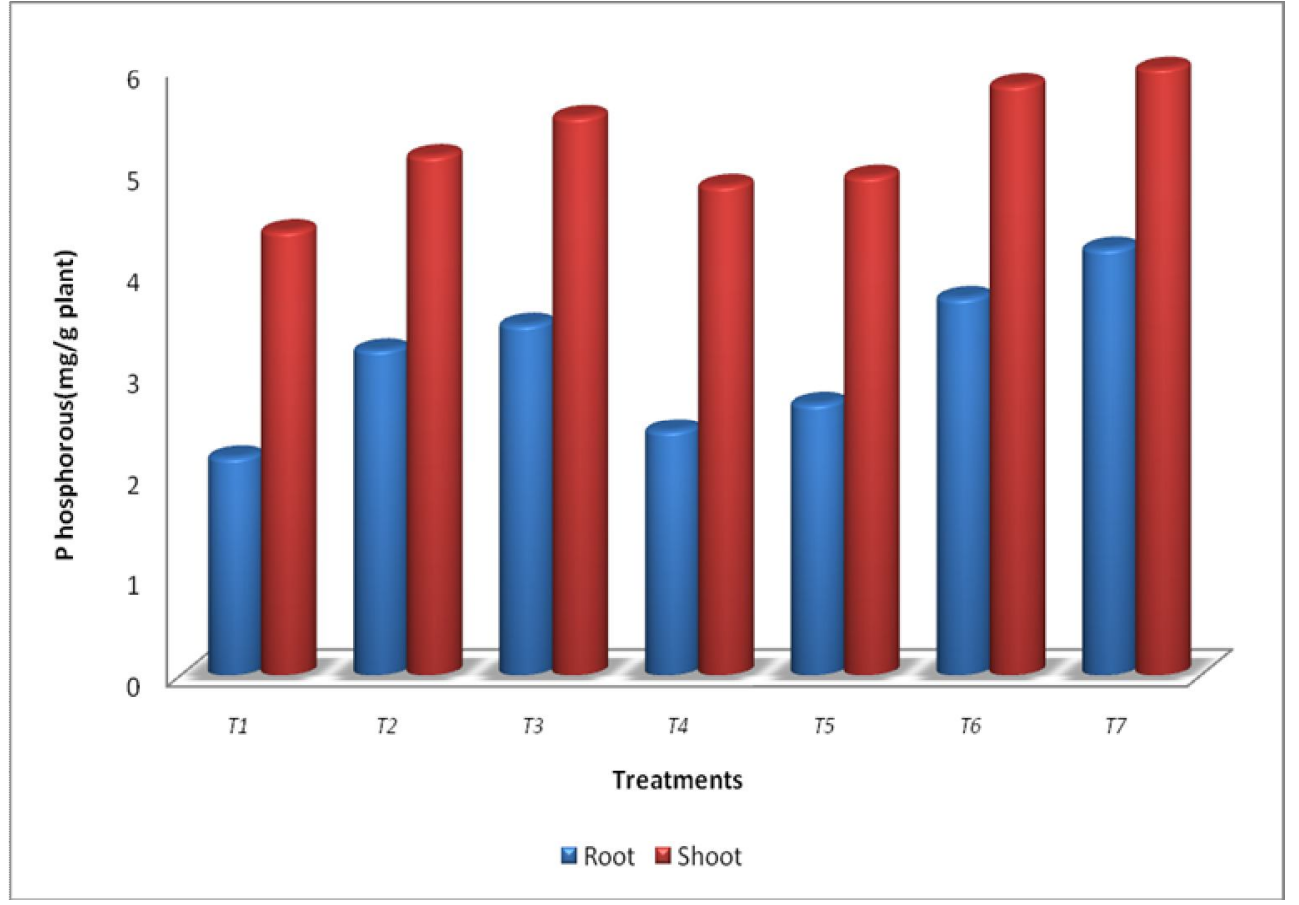

Fig. 1- $\mathrm{N}$ and $\mathrm{P}$ content in the root and shoot of maize grown in different substrates as influenced by AM inoculum at 2 months after inoculation 

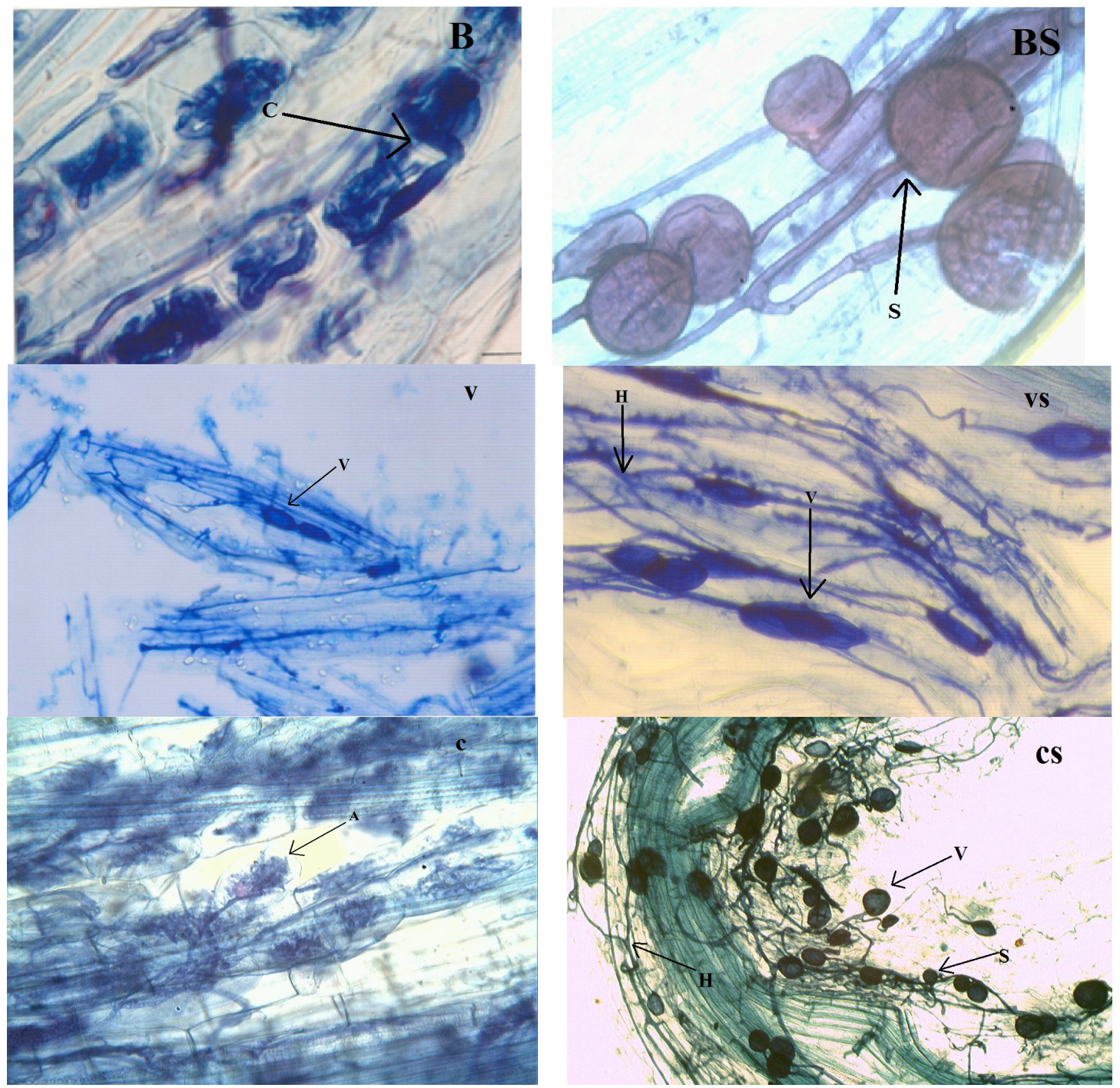

Plate 1- Root colonization of maize by Glomus intraradices (AM) as affected by different substrates

$\mathrm{B}=$ biochar $; \mathrm{BS}=$ biochar $+10 \%$ soil; $\mathrm{V}=$ vermiculite; $\mathrm{VS}=$ vermiculite $+10 \%$ soil; $\mathrm{C}=$ vermicompost; $\mathrm{CS}=$ vermicompost + 10\% soil; Arrow mark with letter indicates, vesicle $(V)$; hyphae $(H)$; arbuscule $(A)$; spore $(\mathrm{S})$ and coil (C). 